\title{
Preface
}

\section{Basic Ideas in Science: The Concept of Law in Science}

\author{
KLAUS MAINZER
}

In the past, the Academy of Europe (Academia Europaea) has organized a series of interdisciplinary conferences on basic concepts in science. These concepts are more or less fundamental in several sciences with high importance in classical and contemporary philosophy. In the past, we considered the concepts of symmetry, complexity, and causality. Many recommended experts from several disciplines took part. The conference papers were published in European Review, the official journal of Academia Europaea.

On 4-5 June 2012, another conference of this series took place at the Klaus Tschira Foundation in Heidelberg, Germany. The conference topic was dedicated to the concept of law in science. In the classical tradition, natural laws were considered as eternal truths of the world. Galileo and Newton even proclaimed them as 'thoughts of God' represented by mathematical equations. In the Kantian tradition, they became categories of the human mind. David Hume criticized their ontological status and demanded their reduction to habituations of sentiments and statistical correlations of observations. In mainstream twentieth-century science, laws were often understood as convenient instruments only, or were even deconstructed in Feyerabend's 'anything goes'. However, the Newtonian paradigm of mathematical laws and models seems also to be extended to the life sciences (e.g. systems biology). Parallel to the developments in the natural sciences, a change of public meaning regarding laws in society can be observed over the last few centuries. In economics, experimental, statistical, and behavioural approaches are favoured. In any case, the ontological basis of laws, sometimes blamed as 'Platonism', seems to be lost. In the beginning of the twenty-first century, the question arises: Are laws still important concepts of science? What is their contemporary meaning and task in different disciplines? Are there already alternative concepts or do laws remain an essential concept of science? 